\title{
COMMENT:
}

\section{WHAT SHOULD WE KNOW ABOUT MAKING RISK COMPARISONS?}

\author{
Paul Slovic and Nancy Kraus \\ Decision Research \\ 1201 Oak Street \\ Eugene, Oregon 97401 \\ and \\ Vincent T. Covello \\ Center for Risk Communication \\ School of Public Health \\ Columbia University \\ New York, New York 10032
}

KEY WORDS: risk communication; risk comparisons, perceived risk, acceptable risk 


\section{What SHOULD We KNOW about MAKING RISK COMPARISONS? \\ Paul Slovic, Nancy Kraus, and Vincent T. Covello}

The study by Roth et al. (1) provides a valuable lesson for risk communicators--test your messages. The factors that determine how a person interprets a risk communication are subtle and not well understood. As a result, those who draft and disseminate risk messages cannot accurately predict how they will be interpreted and what influence they will have.

The results obtained by Roth et al. are surprising in many ways. Particularly surprising is the finding that the comparisons of unrelated risks were rated relatively favorably. Although such comparisons have been strongly recommended for more than 25 years as ways to put risks in perspective $(2,3,4)$, they have been criticized for ignoring many of the quantitative and qualitative factors that determine the perception and acceptance of risk (5). A harsh editorial in Nature, following Lord Rothschild's advocacy of such comparisons (6), described them as "the kindergarten of risk." The data obtained by Roth et al. suggest that these criticisms may have been misplaced and that comparisons among unrelated risks, if framed carefully, may indeed provide valuable insights.

Before breathing new life into comparisons of unrelated risks, we would like to offer several reasons for restraint and further study. The first pertains to the fact that the study by Roth et al. employed only one scenario. In this scenario, respondents were asked to evaluate the comparison statements from the perspective of advising a plant manager who is about to communicate to a concerned community in a non-crisis, non-confrontational atmosphere. Many plant managers must communicate in just such a setting. However, we 
believe that it is important to replicate this study within diverse contexts, including a setting where the community is angry or distrustful as well as a benign setting in which trust, mutual respect, and meaningful public involvement prevail. We would expect comparisons of unrelated risks to be relatively less satisfactory as the context becomes increasingly hostile. Second, other comparison statements should be evaluated in addition to those drafted by Covello et al. (7). Third, we would like to emphasize a point made by Roth et al. and provide some supporting evidence. Roth et al. suggest that the specific comparison of unrelated risks drafted by Covello et al. may have done well because it did not argue that the risk of cancer was acceptable because it was equal to or smaller than other risks that are commonly accepted. Instead, this message stated that the $"$... purpose in making such a comparison is only to put the risk in context" and "... to gain some perspective on the size of the risk."

We believe this to be a critical point. Many comparisons of unrelated risks do not include this qualification. Instead of adopting this modest objective -- i.e., providing perspective -- comparisons of unrelated risks are frequently advanced as a means for setting priorities and determining which risks are acceptable (7). More specifically, they are advocated as a means for determining which risks to ignore, which risks to be concerned about, and how much risk reduction to seek $(2,3,4,8,9)$.

We believe that these arguments are flawed and that risk acceptability depends on a wider range of factors than the probabilities or expected fatality or morbidity estimates that are typically compared. Comparisons that stress acceptability of risk are, therefore, vulnerable to criticism. To support this claim, we would like to offer some additional 
empirical data. We have conducted an experiment in which subjects played the role of jurors in a simulated trial in which a company that supplied asbestos insulation materials was charged with exposing the students and staff of a school to unreasonable risk of disease. In our scenario, the company contended that the use of this product in the school building did not pose a health hazard to the students and staff of the school.

The subjects in this study were 117 persons who answered an ad in a community newspaper. They were assigned to one of three groups, each of which received different information about the risks from asbestos and other hazards. All subjects were given the same background briefing about the nature of asbestos and its health hazards. They were also given information about the trial, which was modeled after several actual court cases in which manufacturers and installers of asbestos materials were sued by parents or school districts. Finally, all subjects were told that an authoritative source had determined that the average concentration of asbestos in the air at the school was .001 fibers per cubic centimeter and that students attending the school for three years faced an increased lifetime fatality risk of 0.23 per million.

The three information conditions differed as follows:

Group 1 received no additional information. They were asked to answer the following questions about risk and guilt:

1. In your opinion, how high is the risk of exposure to the asbestos concentrations found at Jefferson Junior High School?

\begin{tabular}{ccccccc}
$\begin{array}{c}\text { very low } \\
\text { risk }\end{array}$ & & $\begin{array}{c}\text { moderate } \\
\text { risk }\end{array}$ & & \multicolumn{2}{c}{$\begin{array}{c}\text { very high } \\
\text { risk }\end{array}$} \\
1 & 2 & 3 & 4 & 5 & 6 & 7
\end{tabular}


2. If you were on the jury in this case, would you find [the company] guilty or not guilty of exposing the students and staff of Jefferson Junior High School to unreasonable risk of disease resulting from exposure to asbestos fibers introduced into the air by their products?

$$
\text { [ ] guilty [ ] not guilty }
$$

Group II received the same background information followed by Exhibit A (shown in Table 1) comparing the asbestos risk with risks from smoking, diet soft drinks, chest $x-$ rays, peanut butter, and background radiation from living in a brick house. Accompanying Exhibit A was a statement by a (fictitious) expert witness; Dr. A. Davis, called on behalf of the defendant to explain and interpret the risk comparisons in the table. Dr. Davis concluded his explanation with the following opinion:

"So now, if we: look at the risk associated with being exposed to asbestos fibers while attending Jefferson Junior High School for three years, it's less than one -- 0.23 deaths per million to be precise. That's a very small fraction of the risk estimated for drinking diet sodas or even for eating peanut butter sandwiches. So, even though exposure to asbestos at very high levels has been shown to cause disease, I'd have to say, based on my professional experience and as a concerned citizen, that I would have no concern if anyone -- including persons from may own family -- were to attend Jefferson Junior High School."

After examining Exhibit A and reading Dr. Davis' statement, subjects answered the two questions about risk and guilt.

Insert Table 1 about here

Subjects in Group I were also shown the comparisons in Exhibit A after making their judgments and they were asked to answer the two questions a second time. 
Group III was given the same information as Group II, including the table of risk comparisons and the statement by Dr. Davis. In addition, subjects in this group were given a statement by a (fictitious) expert witness for the plaintiff, Dr. P. Stewart, criticizing the comparisons shown in Exhibit A. Dr. Stewart's testimony, which argues that Exhibit A has no logical implications regarding the acceptability of the asbestos in the school, is presented in Table 2.

Insert Table 2 about here

Table 3 presents the mean risk rating and the percentage of guilty judgments for the three information conditions. Data from Group I shows that the 0.23 lifetime risk estimate, presented alone, evoked a moderately high rating of risk and a judgment of guilty by more than half of the subjects. Seventy percent of these same individuals, shown the comparisons in Table 1, subsequently lowered their judgments of risk; no one gave an increased risk evaluation. Judgements of guilt were less influenced by the comparisons in Exhibit A.

Insert Table 3 about here

Group II, which responded only after seeing the risk comparisons, had a significantly lower mean risk judgment $(p<.01)$ and a markedly lower percentage of subjects finding the company guilty $(p<.05)$. Presented without challenge, Exhibit A was clearly effective in reducing subjects' concerns. 
Responses from Group III, however, were virtually the same as those from Group I, suggesting that the effects of the comparisons on perceived risk and judged guilt were fully offset by the critique presented in Table 2 .

Technical analyses of the asbestos problem have generally concluded that the risks to school children are quite small, far lower than the risks to workers who are called upon to remove the asbestos (10). The data shown in Table 3 suggest that this "small risk" does not appear small or acceptable to people when presented as a single estimate $(0.23$ fatalities per million students). The results show how sensitive perceptions of risk and guilt are to contextual information provided by a simple table of comparisons and to a critique that undermines the legitimacy of inferring acceptability of risk from comparisons across diverse hazards.

The results of this modest empirical study should be interpreted with caution. The trial setting was artificial and the arguments were quite abbreviated selections from the many possible ways of presenting, challenging, and counter-challenging the information about asbestos risks. The few prior attempts to examine the content of risk messages, going back to Fischhoff (11) and including the study by Roth et al., are similarly incomplete -more on the order of demonstration studies. Despite being incomplete, these studies do demonstrate that content and context matter in risk communication. If we take this message seriously, we should incorporate a carefully designed and executed evaluation component into every important communication effort.

Recognizing the limitations of our simulated trial, it still seems remarkable to us that the effects of the comparisons in Exhibit A were so easily offset by the critique despite the 
fact that they show the asbestos risk to be minuscule relative to other commonly accepted risks. This suggests to us that the analyses and opinions of technical experts who believe that asbestos in schools should be left in place may not be convincing to the public in an adversarial context. More generally, the impotency of quantitative risk assessment in adversarial settings has important implications for the way that we manage risk in our society. One implication is that those who assess and manage risks need to relate to their constituents over the long term in ways that establish trust, credibility, and mutual respect. In summary, the simplicity and intuitive appeal of comparisons of unrelated risks may be highly deceptive. Many factors appear to play a role in determining whether such comparisons will be useful. Whether these kinds of comparisons ultimately generate more light than heat will depend on the degree to which both the context of risk communication and the content of the messages are sensitive to these factors. 


\section{Table 1}

Exhibit A: Lifetime risks per million persons

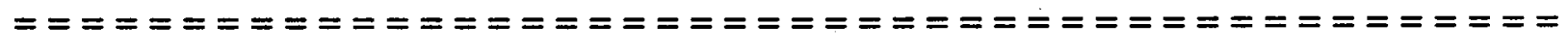
deaths per million persons

Smoking one pack of cigarettes each $\quad 88,000$ day for 20 years

Drinking one diet soft drink

170 containing saccharin per day for a lifetime

Chest X-rays

41

Eating 4 tablespoons of peanut butter

11 per day (aflatoxin)

Living in a brick house (radiation)

Attending Jefferson Junior High School

0.23 for 3 years (asbestos based on .001 fibers per cubic centimeter)

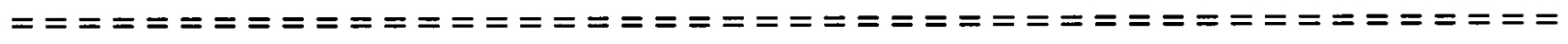


STATEMENT BY DR. P. STEWART, AN EXPERT WITNESS CALLED ON BEHALF OF THE PLAINTIFF, JEFFERSON JR. HIGH SCHOOL, IN TESTIMONY ABOUT THE STATISTICS PRESENTED IN EXHIBIT A.

Dr. Stewart: As I understand it, Exhibit A shows the risk per million persons of dying from the activities listed. The numbers shown on the chart are estimates, based on statistical analyses.

In my opinion, the numbers in this chart are misleading, and fail to have any logical implications for the asbestos decision under consideration.

First, the estimates in the Exhibit may not be accurate, particularly in the case of asbestos. The risk value given for asbestos is based on an average reading of .001 fibers per cubic centimeter. But, at times, the level of asbestos fibers people in the building are exposed to may be much higher (for example, when repair work is being done). The average exposure given in the exhibit may not accurately represent the risk from such higher "peak" concentrations.

My second objection is more fundamental. The fact that one risk is accepted does not necessarily mean that another, lower risk is acceptable.

Acceptability must weigh risks against benefits. The risks from asbestos, no matter how small, are not acceptable if there are no compensating benefits or if there are less risky alternatives that can provide similar benefits.

Furthermore, most of the risks presented in Exhibit A are voluntary activities. Attending a school contaminated by asbestos is involuntary, not under the control of the children who are at risk. The standards for acceptability need to be much stricter for exposing children involuntarily to risk.

So, I'd have to say, as a professional and as a parent of school-age children, that the risks from exposure to the asbestos levels found at Jefferson Junior High may indeed by low. They may be very low. But I wouldn't want to expose my kids even to a theoretical risk of asbestos if I didn't have to. 
Table 3

Perceived Risk and Judgments of Guilt for Three Information Conditions

Mean Perceived
Risk $\quad \begin{gathered}\text { Finding Company } \\ \text { Guilty }\end{gathered}$

\begin{tabular}{lllll}
\hline Group & $\begin{array}{l}\text { Information } \\
\text { Presented }\end{array}$ & $\underline{N}$ & & \\
I. & Lifetime risk & 30 & $3.53(2.13)$ & $54(45)$ \\
II. & $\begin{array}{l}\text { Lifetime risk plus } \\
\text { Exhibit A }\end{array}$ & 27 & 2.48 & 30 \\
III. & $\begin{array}{l}\text { Lifetime risk, } \\
\text { Exhibit A, and } \\
\text { critique of } \\
\text { Exhibit A }\end{array}$ & 60 & 3.53 & 52 \\
& & & & \\
\hline
\end{tabular}

Note: Parenthesized values for Group I summarize responses after being shown Exhibit $A$. Perceived risk decreased for 21 of 30 subjects, remained the same for 9 subjects, and increased for 0 subjects. Two subjects changed their assignments from guilty to not guilty. 


\section{Acknowledgments}

We are indebted to numerous individuals for their assistance with the asbestos trial simulations. In particular, we wish to thank Derry Allen, Kenny S. Crump, Fred Fields, and William Suojanen, without implying that they necessarily concur in our research design or conclusions. 


\section{References}

1. Roth, E., Morgan, G., Fischhoff, B., Lave, L., \& Bostrum, A. (In Press). What do we know about making risk comparisons? Risk Analysis.

2. Sowby, F. D. (1965). Radiation and other risks. Health Physics, 11, 879-887.

3. Rothschild, N. (1978, November). Coming to grips with risk (Address presented on BBC television; reprinted in the Wall Street Journal, May 13, 1979).

4. Cohen, B., \& Lee, I. (1979). A catalog of risks. Health Physics, 36, 707-722.

5. Slovic, P. (1987). Perception of risk. Science, 36, 280-285.

6. Rothschild's numerate arrogance. (1978). Nature, 276, 429.

7. Covello, V. T., Sandman, P. M., \& Slovic, P. (1988). Risk communication, risk statistics, and risk comparisons: A manual for plant managers. Washington, DC: Chemical Manufacturers Association.

8. Lawless, E. W., Jones, M. V., \& Jones, R. M. (1984). Comparative risk assessment: Towards an analytical framework. Kansas City: Midwest Research Institute.

9. Pochin, E. E. (1975). The acceptance of risk. British Medical Bulletin, 31(3), 184-190.

10. Mossman, B. T., Bignon, J., Corn, M., Seaton, A., \& Gee, J. B. L. (1990). Asbestos: Scientific developments and implications for public policy. Science, 247, 294-301.

11. Fischhoff, B. (1981). Informed consent for transient nuclear workers. In R. Kasperson \& R. W. Kates (Eds.), Equity issues in nuclear waste disposal. Cambridge: Oelgeschlager, Gunn, \& Hain. 